\title{
In vitro culture systems: how far are we from optimal conditions?
}

\author{
C. Wrenzycki ${ }^{1}$ \\ Clinic for Veterinary Obstetrics, Gynecology and Andrology of Large and Small Animals, Faculty of Veterinary Medicine, \\ Justus-Liebig-University Giessen, Giessen, Germany.
}

\begin{abstract}
Over the past decades in vitro production (IVP) of bovine embryos has been significantly improved. Nevertheless, embryos generated in vitro still differ from their in vivo produced counterparts. Embryos must adjust to multiple microenvironments at preimplantation stages. Consequently, maintaining or mimicking the in vivo situation in vitro will aid to improve the quality and developmental competence of the resulting embryo.
\end{abstract}

Keywords: cattle, embryo, in vitro production.

\section{Introduction}

The birth of the first IVF calf derived from an in vivo matured oocyte in 1981 (Brackett et al., 1982) and the discovery of heparin as capacitating agent for bull sperm in 1986 (Parrish et al., 1986) were the two key events starting an era of intense research resulting in efficient in vitro production (IVP) systems for preimplantation embryos including in vitro maturation (IVM) of the oocyte to the metaphase II, in vitro fertilization (IVF), and subsequent in vitro culture (IVC) of embryos to the blastocyst stage. The first calves produced entirely from IVM-IVF-IVC were born in 1987 (Fukuda et al., 1990).

Another milestone was the development of ultrasound-guided transvaginal oocyte aspiration in humans and the adoption in the bovine in 1988 (Pieterse et al., 1988). The current technology of OPU/IVP harvesting immature oocytes form living cows can routinely be performed twice a week for an extended period of time without any long-term detrimental effects on the donor's cow fertility (Chastant-Maillard et al., 2003). Attempts were undertaken to combine OPU with colour Doppler ultrasonography which is a useful, noninvasive technique for evaluating ovarian vascular function, allowing a visual observation of the blood flow in a delimited area in the wall of preovulatory follicles (Brännström et al., 1998). Blood flow determinations of individual preovulatory follicles prior to follicular aspiration for IVF therapy provide an important insight on the intrafollicular environment and may predict the developmental competence of the corresponding oocyte (Coulam et al., 1999; Huey et al., 1999). In cattle, it has been shown that the time interval between the individual OPU sessions had an effect on the quality of oocyte and embryos at the molecular level, whereas differences in the perifollicular blood flow did not (Hanstedt et al., 2010). An increase in the blood supply to individual follicles appears to be associated with follicular growth rates, while a reduction seems to be closely related to follicular atresia (Acosta et al., 2003; Acosta 2007). Taken together, OPU can be considered a mature technique and no major improvements should be expected in the technology and its results in the near future. At present the application of IVP combined with ovum pick up (OPU) from valuable donors is increasing (again) due to developing breeding strategies based on genomic selection using SNP (single nucleotide polymorphism) chips. Depending on the chip used, thousands of these SNPs can be analyzed even in a biopsy taken from an embryo. This technology is now reaching routine usage for genomic selection (GS) in cattle (Ponsart et al., 2013).

With regard to IVP efficiency, approximately $80-90 \%$ of immature bovine oocytes undergo nuclear maturation in vitro, about $80 \%$ undergo fertilization, 30 $40 \%$ develop to the blastocyst stage, and around $50 \%$ of the transferred embryos establish and maintain a pregnancy (Wrenzycki et al., 2007; Galli et al., 2014; Lonergan et al., 2016).

\section{IVM}

Cumulus-oocyte-complexes (COC) collected from ovaries of slaughtered or euthanized animals or from living animals via ovum pick-up (OPU) require in vitro maturation (IVM) as they are arrested at the germinal vesicle $(\mathrm{GV})$ stage. Maturation involves a series of events that begin in fetal life with the initiation of meiosis. At birth, the oocytes are arrested at the diplotene stage (germinal vesicle stage, GV). After puberty when they are exposed to preovulatory surges of LH and FSH they proceed with meiosis and are arrested again at the metaphase II, the stage at which they are ovulated (Monniaux et al., 2014). In addition, optimal conditions for cumulus cells surrounding the oocyte need to be considered as there is a complex bidirectional communication between these two cell types (Gilchrist, 2011; Monniaux, 2016).

Proper maturation of the oocyte to metaphase II is a prerequisite for fertilization and pre-implantation development. It is possible to achieve blastocyst rates of up to $70 \%$ if in vivo matured oocytes are used. In contrast, if oocytes are matured in vitro, blastocyst rates are only half that of those matured in vivo. This rather limited success may be attributed to the heterogeneous population of oocytes which are normally retrieved from follicles of 3-8 $\mathrm{mm}$ rather than from preovulatory follicles. In contrast to the in vivo ovulated oocyte, these oocytes lack development up to the preovulatory stage 
and are matured in vitro. Therefore, much effort has been devoted to the establishment of noninvasive and non-perturbing means for selecting the most competent oocytes (Fair, 2010; Krisher, 2013; Wrenzycki and Stinshoff, 2013).

IVM of immature oocytes occurs by a different mechanism from that of in vivo matured oocytes. IVM is initiated immediately following the removal of the immature oocyte from small antral follicles, and such oocytes may have neither the time nor the correct environment to complete the necessary changes required for subsequent successful development (Krisher, 2013; Wrenzycki and Stinshoff, 2013; Lonergan and Fair, 2016).

Recently, the so-called simulated physiological oocyte maturation (SPOM) system has been introduced (Albuz et al., 2010). It prevented spontaneous resumption of meiosis after mechanical oocyte retrieval and thereby improved in vitro embryo development. However, due to the fact that similar outcomes were not easily to achieve, a revised version has been reported (Gilchrist et al., 2015). At the moment, most laboratories practicing IVM of cattle oocytes use a relatively simple oocyte maturation system.

\section{IVF}

IVF is a complex procedure whose success requires appropriate oocyte maturation, sperm selection, sperm capacitation and IVF media.

Semen samples contain a heterogeneous population of sperm cells. In vivo, the sperm cells are thought to be selected by various mechanisms within the female reproductive tract, with the result that the small number of spermatozoa found near to the oocyte are typically those best able to penetrate the zona pellucida and fertilize the oocyte. When using IVF, however, these natural selection mechanisms are circumvented. The most common method for preparing spermatozoa for IVF is by centrifugation them through a concentration gradient, such as a $45 \%$ Percoll mixture layered on a $90 \%$ solution.

A variant of colloid centrifugation using only one layer of colloid (in which case there is no gradient) has been developed. Single-layer centrifugation (SLC) through a species-specific colloid has also been shown to be effective in selecting spermatozoa with good motility, normal morphology and intact chromatin (Thys et al., 2009; Goodla et al., 2014; Morrell et al., 2014; Gloria et al., 2016). An alternative method is the swim-up procedure. The disadvantages of swim-up are that it takes approximately $45-60 \mathrm{~min}$ to do and only 10 $20 \%$ of the spermatozoa in the sample are recovered. For colloid centrifugation, only $25 \mathrm{~min}$ preparation time is needed (including the centrifugation) and a recovery rate of $>50 \%$ is commonly achieved (Thys et al., 2009), although this does depend on the sperm quality of the original sample.

Once IVM is complete, oocytes are ready to be fertilized. This involves the coincubation of oocytes with sperm cells. Most laboratories allow for 18-19 h of coincubation. The changes a sperm cell has to go through before it can fertilize an oocyte are summarized under the term capacitation. Media have been developed to support this process, e.g. TALP medium. As mentioned earlier, the primary capacitation agent is heparin. The majority of semen used for IVF is frozenthawed. The most common final sperm concentration used in the IVF drop is $1 \times 10^{6} \mathrm{sperm} / \mathrm{ml}$.

\section{IVC}

IVC of bovine embryos is the last step in the IVP procedure and involves approximately 6 days of culture from the presumptive zygote onwards. The most common media for culturing bovine embryos are variations of the original synthetic oviduct fluid (SOF) medium (Tervit et al., 1972). SOF is now part of most routine bovine IVP systems with/without serum. Embryos are cultured in only one medium throughout the entire time or a sequential system in which the medium formulation changes at certain time points in the culture period. These sequential media try to mimic the physiological changes that embryos encounter in vivo when they move down the oviducts and into the uterus. Parameters which vary from lab to lab are diverse, e.g. the volume of medium and the atmosphere in the incubator.

In vitro culture (IVC) conditions have been enhanced in the last years, mainly by adjustment of media formulations. However, while over 30\% blastocyst formation could be achieved in most culture systems, it soon became obvious that quantity did not always match quality (Wrenzycki et al., 2005; 2007 Lonergan et al., 2006;) and that serum supplementation was detrimental to embryo/fetal development as one main causal factor of the so-called large offspring syndrome (LOS), characterized by abnormally advanced embryonic and fetal growth, altered gene expression patterns, and high perinatal losses (Young et al., 1998; Lazzari et al., 2002). A large field study demonstrated that the incidence of LOS was greatly reduced by in vitro culture in cell-free and serum-free SOF media (van Wagtendonk-de Leeuw et al., 2000). Such observations highlight the importance of the post-fertilization culture environment for the quality of the resulting blastocyst. However, the existence of diverse embryo culture media and methods makes it very challenging to define the optimal components of embryo culture media.

The success of an IVP laboratory may stem not only from improvements of the IVC per se, but from the entire IVP system (Gardner, 2008; Baltz, 2012; Leese, 2012). The latter includes: incubation conditions, gas phase, culture media, oil overlay, plastic ware, and embryo density and the volume of the medium. In addition, the skills of the staff involved in the entire process have to be considered as part of the system.

In general, IVP can be considered to be at an advanced stage of progress. However, an aspect that may change in the future is automation and miniaturization of the IVP process by better mimicking the in vivo environment, e.g. using microfluidics (Wheeler et al., 2007) or an encapsulation technology (Blockeel et al., 2009) to obtain IVP embryos of similar 
quality as the in vivo ones.

\section{Quality assessment of preimplantation embryos}

The ultimate test of the quality of an embryo is its ability to produce live and healthy offspring after transfer to a recipient. Morphology and the proportion developing to the blastocyst stage are used as criteria to assess developmental competence. Evaluation of embryo morphology remains the method of choice for selection of viable embryos prior to transfer. It is the most practical and clinically useful approach to assess of embryo viability (Van Soom et al., 2003). A bovine embryo grading system developed previously (Lindner and Wright, 1983) is, with minor modifications, still widely applied in this field (Hasler, 2001), listed in the IETS Manual. However, sometimes embryo morphology alone is not accurate enough to act as the sole criterion for the prediction of embryo developmental potential in vivo. Better non-invasive markers and improved techniques are required. These techniques can provide more valuable information on embryo viability. For examples, measurement of oxygen consumption using the nanorespirometer (Lopes et al., 2007) as well as amino acid profiling (Sturmey et al., 2010) can be employed to predict developmental competence and embryo viability. Although noninvasive approaches are improving, invasive ones have been extremely helpful in finding candidate genes to determine embryo quality (Wrenzycki et al., 2007, Rizos et al., 2008; Graf et al., 2014).

\section{Conclusion}

In vitro production (IVP) of bovine embryos follows a well-developed procedure that is commercially available for this species. However, despite all the improvements in oocyte and embryo culture, at best only $30-35 \%$ of immature bovine COC develop to the blastocyst stage which might represent a reasonable efficiency. But the in vivo situation still cannot be mimicked sufficiently well. The quality of the embryos produced is still impaired in comparison with their in vivo counterparts. This suggests that there are still improvements to be made in increasing oocyte and embryo developmental competence. More basic research is needed on molecular mechanisms e.g. epigenetic reprogramming during early embryonic development as well as detailed studies on the composition and interactions of culture media. By altering the conditions of oocyte maturation and embryo culture respectively to mirror more closely that which occurs in vivo, it may be possible to produce not only more blastocyst stage embryos, but more importantly, blastocysts of better quality.

\section{References}

Acosta TJ, Hayashi KG, Ohtani M, Miyamoto A. 2003. Local changes in blood flow within the preovulatory follicle wall and early corpus luteum in cows. Reproduction, 125:759-767.
Acosta TJ. 2007. Studies of follicular vascularity associated with follicle selection and ovulation in cattle. J Reprod Dev, 53:39-44.

Albuz FK, Sasseville M, Lane M, Armstrong DT, Thompson JG, Gilchrist RB. 2010. Simulated physiological oocyte maturation (SPOM): a novel in vitro maturation system that substantially improves embryo yield and pregnancy outcomes. Hum Reprod, 25:2999-3011.

Baltz JM. 2012. Media composition: salts and osmolality. Methods Mol Biol, 912:61-80.

Blockeel C, Mock P, Verheyen G, Bouche N, Le Goff P, Heyman Y, Wrenzycki C, Höffmann K, Niemann H, Haentjens P, de Los Santos MJ, FernandezSanchez M, Velasco M, Aebischer P, Devroey P, Simón C. 2009. An in vivo culture system for human embryos using an encapsulation technology: a pilot study. Hum Reprod, 24:790-796.

Brackett BG, Bousquet D, Boice ML, Donawick WJ, Evans JF, Dressel MA. 1982. Normal development following in vitro fertilization in the cow. Biol Reprod, 27:147-158.

Brännström M, Zackrisson U, Hagström HG, Josefsson B, Hellberg P, Granberg S, Collins WP, Bourne T. 1998. Preovulatory changes of blood flow in different regions of the human follicle. Fertil Steril, 69:435-442.

Chastant-Maillard S, Quinton H, Lauffenburger J, Cordonnier-Lefort N, Richard C, Marchal J, Mormede P, Renard JP. 2003. Consequences of transvaginal follicular puncture on well-being in cows. Reproduction, 125:555-563.

Coulam CB, Goodman C, Rinehart JS. 1999. Colour Doppler indices of follicular blood flow as predictors of pregnancy after in-vitro fertilization and embryo transfer. Hum Reprod, 14:1979-1982.

Fair T. 2010. Mammalian oocyte development: checkpoints for competence. Reprod Fertil Dev, 22:1320.

Fukuda Y, Ichikawa M, Naito K, Toyoda Y. 1990. Birth of normal calves resulting from bovine oocytes matured, fertilized, and cultured with cumulus cells in vitro up to the blastocyst stage. Biol Reprod, 42:114-9.

Galli C, Duchi R, Colleoni S, Lagutina I, Lazzari G. 2014. Ovum pick up, intracytoplasmic sperm injection and somatic cell nuclear transfer in cattle, buffalo and horses: from the research laboratory to clinical practice. Theriogenology, 81:138-1351.

Gardner DK. 2008. Dissection of culture media for embryos: the most important and less important components and characteristics. Reprod Fertil Dev, 20:9-18

Gilchrist RB. 2011. Recent insights into oocyte-follicle cell interactions provide opportunities for the development of new approaches to in vitro maturation. Reprod Fertil Dev, 23:23-31.

Gilchrist RB, Zeng HT, Wang X, Richani D, Smitz J, Thompson JG. 2015. Reevaluation and evolution of the simulated physiological oocyte maturation system. Theriogenology, 84:656-657.

Gloria A, Carluccio A, Wegher L, Robbe D, Befacchia G, Contri A. 2016. Single and double layer 
centrifugation improve the quality of cryopreserved bovine sperm from poor quality ejaculates. J Anim Sci Biotechnol, 7:30.

Goodla L, Morrell JM, Yusnizar Y, Stålhammar H, Johannisson A. 2014. Quality of bull spermatozoa after preparation by single layer centrifugation. $J$ Dairy $S c i$ 97:2204-2212.

Graf A, Krebs S, Heininen-Brown $M$, Zakhartchenko V, Blum H, Wolf E. 2014. Genome activation in bovine embryos: review of the literature and new insights from RNA sequencing experiments. Anim Reprod Sci, 149:46-58.

Hanstedt A, Wilkening S, Brüning K, Honnens Ä, Wrenzycki C. 2010. Effect of perifollicular blood flow on the quality of oocytes collected during repeated OPU sessions. Reprod Fertil Dev, 22:223.

Hasler JF. 2001. The current status and future of commercial embryo transfer in cattle. Anim Reprod Sci, 79:245-264.

Huey S, Abuhamad A, Barroso G, Hsu MI, Kolm P, Mayer J, Oehninger S. 1999. Perifollicular blood flow Doppler indices, but not follicular pO2, pCO2, or $\mathrm{pH}$, predict oocyte developmental competence in in vitro fertilization. Fertil Steril, 72:707-712.

Krisher RL. 2013. In vivo and in vitro environmental effects on mammalian oocyte quality. Annu Rev Anim Biosci, 1:393-417.

Lazzari G, Wrenzycki C, Herrmann D, Duchi R, Kruip T, Niemann H, Galli C. 2002. Cellular and molecular deviations in bovine in vitro-produced embryos are related to the large offspring syndrome. Biol Reprod, 67:767-775.

Leese HJ. 2012. Metabolism of the preimplantation embryo: 40 years on. Reproduction, 143:417-427.

Lindner GM, Wright RW Jr. 1983. Bovine embryo morphology and evaluation. Theriogenology, 20:407416

Lonergan P, Fair T, Corcoran D, Evans AC. 2006 Effect of culture environment on gene expression and developmental characteristics in IVF-derived embryos. Theriogenology, 65:137-152.

Lonergan P, Fair T. 2016. Maturation of oocytes in vitro. Annu Rev Anim Biosci, 15:255-268.

Lonergan P, Fair T, Forde N, Rizos D. 2016. Embryo development in dairy cattle. Theriogenology, 86:270-277. Lopes AS, Wrenzycki C, Ramsing NB, Herrmann D, Niemann $H$, Lovendahl $P$, Greve $T$, Callesen $H$ 2007. Respiration rates correlate with mRNA expression of G6PD and GLUT1 genes in individual bovine in vitro-produced blastocysts. Theriogenology, 68:223-236

Monniaux D, Clément F, Dalbiès-Tran R, Estienne A, Fabre S, Mansanet C, Monget P. 2014. The ovarian reserve of primordial follicles and the dynamic reserve of antral growing follicles: what is the link? Biol Reprod, 90:85.

Monniaux D. 2016. Driving folliculogenesis by the oocyte-somatic cell dialog: lessons from genetic models. Theriogenology, 86:41-53.

Morrell JM, Rodriguez-Martinez H, Andersson M. 2014. Colloid centrifugation selects normal spermatozoa from polymorphic bull ejaculates: a case study. Reprod Domest Anim, 49:281-284.

Parrish JJ, Susko-Parrish JL, Leibfried-Rutledge ML, Critser ES, Eyestone WH, First NL. 1986. Bovine in vitro fertilization with frozen-thawed semen. Theriogenology, 25:591-600.

Pieterse MC, Kappen KA, Kruip TA, Taverne MA. 1988. Aspiration of bovine oocytes during transvaginal ultrasound scanning of the ovaries. Theriogenology, 30:751-762.

Ponsart C, Le Bourhis D, Knijn H, Fritz S, GuyaderJoly C, Otter T, Lacaze S, Charreaux F, Schibler L, Dupassieux D, Mullaart E. 2013. Reproductive technologies and genomic selection in dairy cattle. Reprod Fertil Dev, 26:12-21.

Rizos D, Clemente M, Bermejo-Alvarez $P$, de La Fuente J, Lonergan P, Gutiérrez-Adán A. 2008. Consequences of in vitro culture conditions on embryo development and quality. Reprod Domest Anim, 43(suppl. 4):44-50.

Sturmey RG, Bermejo-Alvarez P, Gutierrez-Adan A, Rizos D, Leese HJ, Lonergan P. 2010. Amino acid metabolism of bovine blastocysts: a biomarker of sex and viability. Mol Reprod Dev, 77:285-296.

Tervit HR, Whittingham DG, Rowson LE. 1972. Successful culture in vitro of sheep and cattle ova. $J$ Reprod Fertil, 30:493-497.

Thys, M, Vanadele L, Morrell JM, Mestach J, Van Soom A, Hoogewijs M, Rodriguez-Martinez H. 2009. In vitro fertilising capacity of frozen-thawed bull spermatozoa separated by colloidal centrifugation through single-layer or gradients. Reprod Domest Anim, 44:390-394.

Van Soom A, Mateusen B, Leroy J, De Kruif A. 2003. Assessment of mammalian embryo quality: what can we learn from embryo morphology? Reprod Biomed Online, 7:664-670.

van Wagtendonk-de Leeuw AM, Mullaart E, de Roos AP, Merton JS, den Daas JH, Kemp B, de Ruigh L. 2000. Effects of different reproduction techniques: AI MOET or IVP, on health and welfare of bovine offspring. Theriogenology, 53:575-597.

Wheeler MB, Walters EM, Beebe DJ. 2007. Toward culture of single gametes: the development of microfluidic platforms for assisted reproduction. Theriogenology, 68(suppl. 1):S178-89.

Wrenzycki C, Herrmann D, Lucas-Hahn A, Korsawe K, Lemme E, Niemann H. 2005. Messenger RNA expression patterns in bovine embryos derived from in vitro procedures and their implications for development. Reprod Fertil Dev, 17:23-35.

Wrenzycki C, Herrmann D, Niemann H. 2007. Messenger RNA in oocytes and embryos in relation to embryo viability. Theriogenology, 68(suppl. 1):S77-83.

Wrenzycki C, Stinshoff H. 2013. Maturation environment and impact on subsequent developmental competence of bovine oocytes. Reprod Domest Anim, 48(suppl. 1):38-43.

Young LE, Sinclair KD, Wilmut I. 1998. Large offspring syndrome in cattle and sheep. Rev Reprod, 3:155-163 